University of Wollongong

Research Online

Faculty of Engineering - Papers (Archive)

Faculty of Engineering and Information

Sciences

$1-1-2010$

\title{
Role of microstructure in susceptibility of X70 pipeline steel to hydrogen embrittlement
}

\author{
Daniel Hejazi \\ University of Wollongong, dh712@uow.edu.au \\ Ayesha J. Haq \\ University of Wollongong, ayesha@uow.edu.au \\ Nima Yazdipour \\ University of Wollongong, nimayaz@uow.edu.au \\ Druce P. Dunne \\ University of Wollongong, druce@uow.edu.au \\ F Barbaro \\ University of Wollongong, fbarbaro@uow.edu.au
}

See next page for additional authors

Follow this and additional works at: https://ro.uow.edu.au/engpapers

Part of the Engineering Commons

https://ro.uow.edu.au/engpapers/4184

\section{Recommended Citation}

Hejazi, Daniel; Haq, Ayesha J.; Yazdipour, Nima; Dunne, Druce P.; Barbaro, F; and Pereloma, E V.: Role of microstructure in susceptibility of X70 pipeline steel to hydrogen embrittlement 2010, 162-165.

https://ro.uow.edu.au/engpapers/4184

Research Online is the open access institutional repository for the University of Wollongong. For further information contact the UOW Library: research-pubs@uow.edu.au 


\section{Authors}

Daniel Hejazi, Ayesha J. Haq, Nima Yazdipour, Druce P. Dunne, F Barbaro, and E V. Pereloma 


\title{
Role of Microstructure in Susceptibility to Hydrogen Embrittlement of
}

\section{X70 Microalloyed Steel}

\author{
Daniel Hejazi ${ }^{1}$, Ahmed Saleh ${ }^{1, a}$, ,Ayesha $\mathrm{Haq}^{1}$, Druce Dunne ${ }^{1, \mathrm{~b}}$, Andrzej \\ Calka $^{1}$, Azdiar A. Gazder ${ }^{2 c}$ and Elena V. Pereloma ${ }^{1,2, d}$ \\ ${ }^{1}$ School of Mechanical, Materials and Mechatronic Engineering, University of Wollongong, \\ NSW 2522, Australia \\ ${ }^{2}$ UOW Electron Microscopy Centre, University of Wollongong, NSW 2519, Australia \\ aasaleh@uow.edu.au, bdruce@uow.edu.au, 'azdiar@uow.edu.au, ${ }^{\text {delenap@uow.edu.au }}$
}

Keywords: microalloyed steel, hydrogen induced cracking, electrolytic charging, energy dispersive X-ray spectroscopy, electron back scattering diffraction.

\begin{abstract}
The effect of phases and steel processing on hydrogen uptake (diffusible and residual), surface and internal damage were evaluated using optical and scanning electron microscopy. The results have shown the fastest formation of blisters in ferrite-pearlite microstructure of strip, followed by equaixed ferrite-pearlite microstructure in normalised condition, then by ferrite-bainite microstructure. No blistering was observed in heat affected zone samples for up to 24 hrs charging. Analysis of hydrogen-induced cracking using electron back scattering diffraction has revealed that crack propagation has predominantly intragranular character without a clear preference on $\{001\}$, $\{110\},\{112\}$ and $\{123\}$ planes and is independent of the steel microstructure and prior processing.
\end{abstract}

\section{Introduction}

Hydrogen-induced blistering and internal cracking can develop in steels without application of external load, when they are exposed to an environment with a high hydrogen content. This is typical for pipeline steels and pressure vessels in contact with wet hydrogen sulphide or hydrocarbons [1, 2]. Similar external and internal damage was observed after cathodic hydrogen charging of steels [3-5]. Ren et al. [4] has proposed that internal cavities can occur by the aggregation of hydrogen atoms and vacancies at trapping sites in the microstructure, resulting in blister formation and growth if cavity is proximate to the surface. On reaching a critical size the internal hydrogen-filled cavity can initiate cracking at the edges of the cavity due to to the internal hydrogen pressure. It has been reported that grain boundaries, interfaces between inclusions and the matrix and/or phase interfaces can act as hydrogen trapping sites for nucleation of cavities [4-9]. Of these, interfaces between oxide inclusions and matrix are deemed to be the most common sites for cavity nucleation and crack extension [8,9]. Development of hydrogen-induced cracking (HIC) has adverse effects on mechanical properties and service life of steels. Thus, many efforts have been focused on the control of microstructural homogeneity and cleanliness of the steel. In addition to microstructural features, crystallographic texture and grain-boundary distribution can also play a significant role in determining the characteristics of HIC. It was shown that steels with $\{001\} N D$ fibre and close-to-random textures are more susceptible to HIC, whereas \{111\}ND fibre textures increase HIC resistance [10].

To date, the majority of research has been on the effects of the inclusions and processing parameters on HIC for the same microstructures in steels, whereas different microstructures were studied for different steel grades. In the present study, the kinetics of crack initiation at cavities and blisters formation are studied as a function of the microstructure in microalloyed X70 steel. 
Particular attention is given to crystallography of HIC using the advanced electron back scattering diffraction (EBSD) technique.

\section{Experimental Procedures}

Commercial X70 pipeline steel manufactured by BlueScope Steel Ltd, with the nominal composition given in Table 1, was received in the form of transfer bar and strip. Simulations of coarse-grained heat affected zone (HAZ) and normalising of transfer bar $\left(950^{\circ} \mathrm{C}, 20\right.$ minutes) were carried out using tubular furnace with either quenching or slow cooling, respectively. The details are available elsewhere [11]. Electrolytical charging of $1 \mathrm{~mm}$ thick samples was carried out at a current density of $50 \mathrm{~mA} / \mathrm{cm}^{2}$ in $1 \mathrm{M} \mathrm{H}_{2} \mathrm{SO}_{4}$ with $250 \mathrm{mg} / \mathrm{L}$ of $\mathrm{NaAsO}_{2}$.

After charging, the samples were either stored in liquid nitrogen before hydrogen testing using hot extraction or immediately positioned for diffusible hydrogen determination using mercury according to AS/NZS 3752:2006 [12].

Table 1. Chemical composition of the studied steel, wt.\%.

\begin{tabular}{|c|c|c|c|c|c|c|c|c|c|c|c|c|c|}
\hline $\mathrm{C}$ & $\mathrm{P}$ & $\mathrm{Mn}$ & $\mathrm{Si}$ & $\mathrm{Ni}$ & $\mathrm{Cr}$ & $\mathrm{Mo}$ & $\mathrm{Cu}$ & $\mathrm{Al}$ & $\mathrm{Nb}$ & $\mathrm{Ti}$ & $\mathrm{V}$ & $\mathrm{S}$ & $\mathrm{N}$ \\
\hline 0.07 & 0.01 & 1.14 & 0.22 & 0.02 & 0.03 & 0.1 & 0.02 & 0.02 & 0.06 & 0.02 & 0.002 & 0.002 & 0.004 \\
\hline
\end{tabular}

For microstructure characterisation, specimens were wire-cut perpendicular to the blister surface, then mechanically ground and polished. Energy Dispersive X-Ray Spectroscopy (EDXS) and EBSD studies were conducted using a JEOL 7001F Field Emission Gun - Scanning Electron Microscope (FEG-SEM) equipped with a XMax Oxford Instruments EDXS detector and with a Nordlys-II(S) EBSD camera and the Oxford Instruments AZtec acquisition software suite operating at $15 \mathrm{kV}$, 3nA and $15 \mathrm{~mm}$ working distance. Depending on the sample condition, the step size varied between 0.15 to $0.3 \mu \mathrm{m}$.

Initial post processing of the raw data consisted of removing misindexes and wild spikes and addressing pseudo-symmetry issues using the HKL - Channel $5^{\mathrm{TM}}$ software package. Low-angle boundaries (LAGBs) comprise misorientations between $2^{\circ}$ and $15^{\circ}$, whereas high-angle boundaries (HAGBs) extend from $15^{\circ}$ onwards. Thereafter the standard methodology for trace analysis [13] was used to investigate HIC.

\section{Results and Discussion}

The microstructure of strip consisted of banded ferrite-pearlite microstructure (BFP) (Fig. 1a), whereas normalised transfer bar had equaixed ferrite-pearlite microstructure (EFP) (Fig. 1b) with 14 $\mu \mathrm{m}$ average ferrite grain size. The microstructure of transfer bar consisted of quasi-polygonal ferrite and granular bainite containing austenite-martensite (MA) islands (FGB) (Fig. 1c), whereas the HAZ had coarse bainitic ferrite (BF) laths with interlayers of austenite (Fig. 1d). A summary of diffusible and residual amounts of hydrogen present in the microstructure of the samples charged for 3 hrs are given in Table 2. The EFP microstructure shows the lowest diffusible hydrogen content followed by BFP, FGB and BF which had the highest dislocation density. This trend is associated with the number of reversible hydrogen traps (dislocations, subgrain boundaries, etc.) present in the microstructure. In contrast, the HAZ BF microstructure exhibited the lowest residual hydrogen content followed by EFP, FGB and BFP microstructures. Due to the similarity of casting and roughing rolling schedules for all of the microstructures studied, the density of irreversible trapping sites at inclusions (oxides, MnS, etc.) are assumed to be the same. Therefore, differences in grain size, volume fraction and types of the phases are considered to be the main factors determining the trend of residual hydrogen content. 
The appearance of blisters on the surface of the samples (Fig. 2a) was registered after different charging times; 2 hrs for BFP, 3 hrs for EFP and 15 hrs for FGB samples, whereas no blistering was recorded for BF sample after charging for 24 hrs. The latter observation may be related to the low amount of residual hydrogen in this condition and a high number of reversible hydrogen traps (Table 2), which precluded formation of critical sized nuclei. The major cracks were located within the sample under the blister parallel to the surface with smaller cracks extending upwards towards the edges of the blisters, providing pathways for internal pressure release (Figs. 1a-1c).

Table 2 Diffusible and residual hydrogen concentrations (ppm) and fraction of various crack planes in different microstructures.

\begin{tabular}{|c|c|c|c|c|c|c|}
\hline & Diffusible & Residual & $\mathbf{\{ 0 0 1}\}$ & $\mathbf{\{ 1 1 0 \}}$ & $\mathbf{\{ 1 1 2}\}$ & $\{\mathbf{1 2 3}\}$ \\
\hline BFP & $3.61 \pm 0.8$ & $3.02 \pm 0.07$ & 0.22 & 0.33 & 0.28 & 0.17 \\
\hline EFP & $2.9 \pm 0.3$ & $1.5 \pm 0.1$ & 0.10 & 0.20 & 0.50 & 0.20 \\
\hline FGB & $3.57 \pm 0.4$ & $1.77 \pm 0.4$ & 0.30 & 0.20 & 0.26 & 0.24 \\
\hline BF & $6.29 \pm 0.8$ & $1 \pm 0.1$ & N/A & N/A & N/A & N/A \\
\hline
\end{tabular}
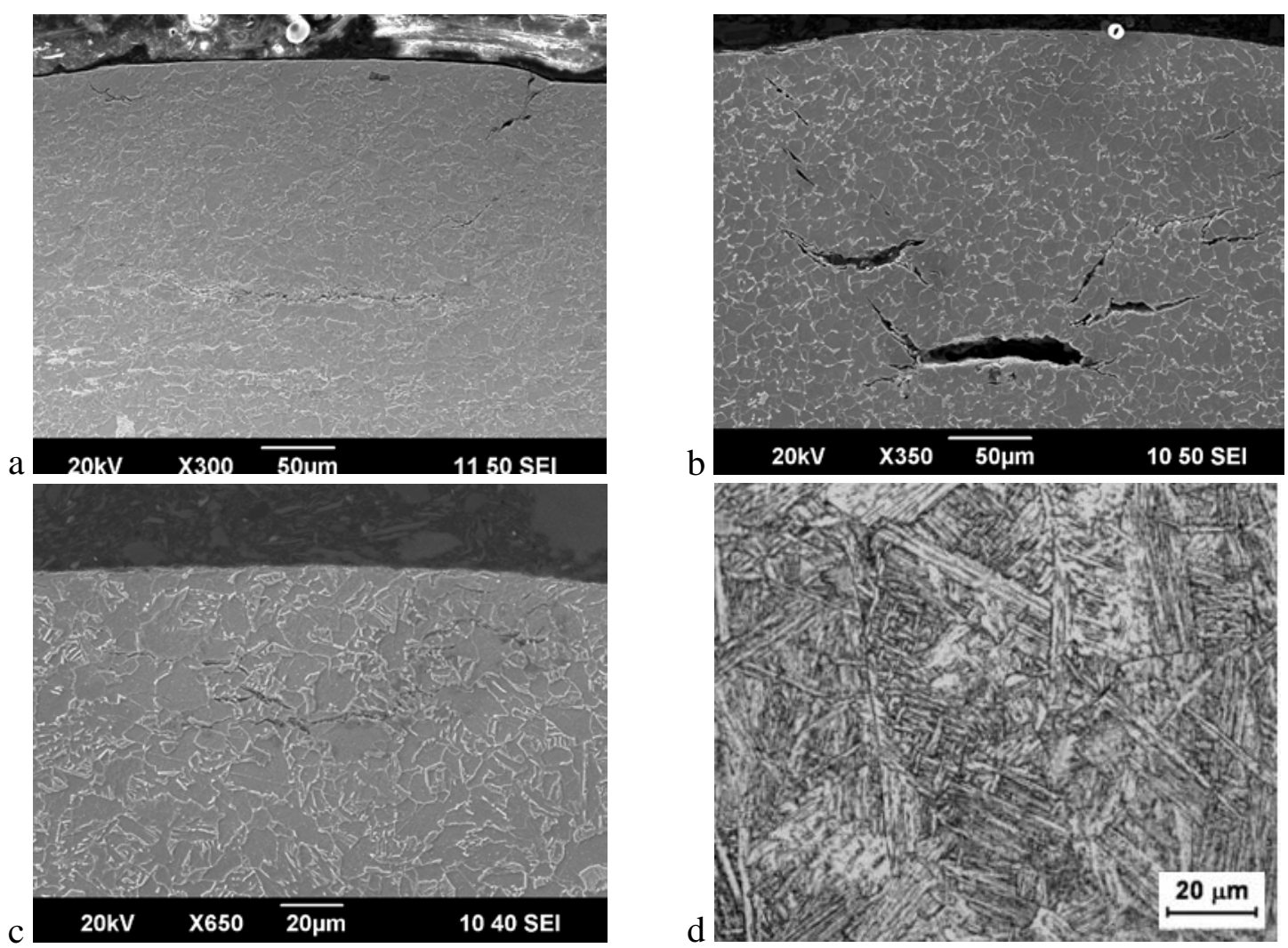

Fig. 1. Micrographs showing the microstructure and cracks under a blister in banded ferritepearlite (a), equaixed ferrite-pearlite (b), quasi-polygonal ferrite and granular bainite (c) and coarse bainitic ferrite laths with martensite-austenite interlayers (d).

X-ray mapping showed that in some cases crack initiation took place at inclusion/matrix interfaces, as can be seen in Fig. 3. These inclusions were identified as $\mathrm{Al}$, Ca oxides. This is in agreement with [9], where crack initiation was predominantly observed at Si or Al-enriched oxides. However, many cracks did not contain any identifiable inclusions and, due to their location, it is likely that, similar to conclusions in [7], interfaces between ferrite and MA constituent or ferrite/pearlite colonies can serve as crack initiation sites.

Crack propagation was predominantly transgranular, as only few intergranular cracks were found (Fig. 4). Cracks were developed irrespective of the microstructure across ferrite grains, pearlite colonies or granular bainite. Only in some instances the cracks were partially following 
ferrite/pearlite (Fig. 2b) or ferrite/MA interfaces. This contradicts conclusions by Lee and Chan [6] that that the cracking occurs predominantly along bands of pearlite colonies in the banded ferritepearlite structure. This dominant intragranular cracking is also in disagreement with intergranular HIC observed in warm rolled API X52 steel with ferrite-pearlite microstructure [10].
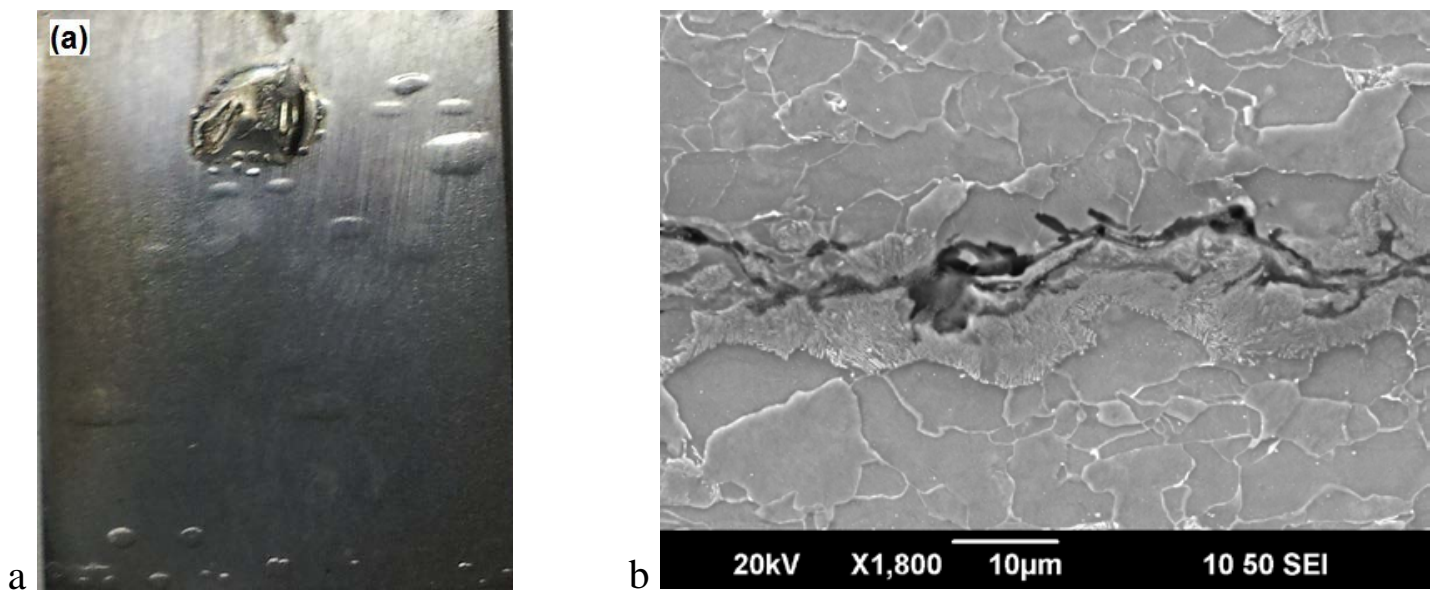

Fig. 2. Formation of blisters along the rolling direction in the areas of banded pearlite in BFP sample after 3 hrs (a) and hydrogen-induced cracking below a blister (b).
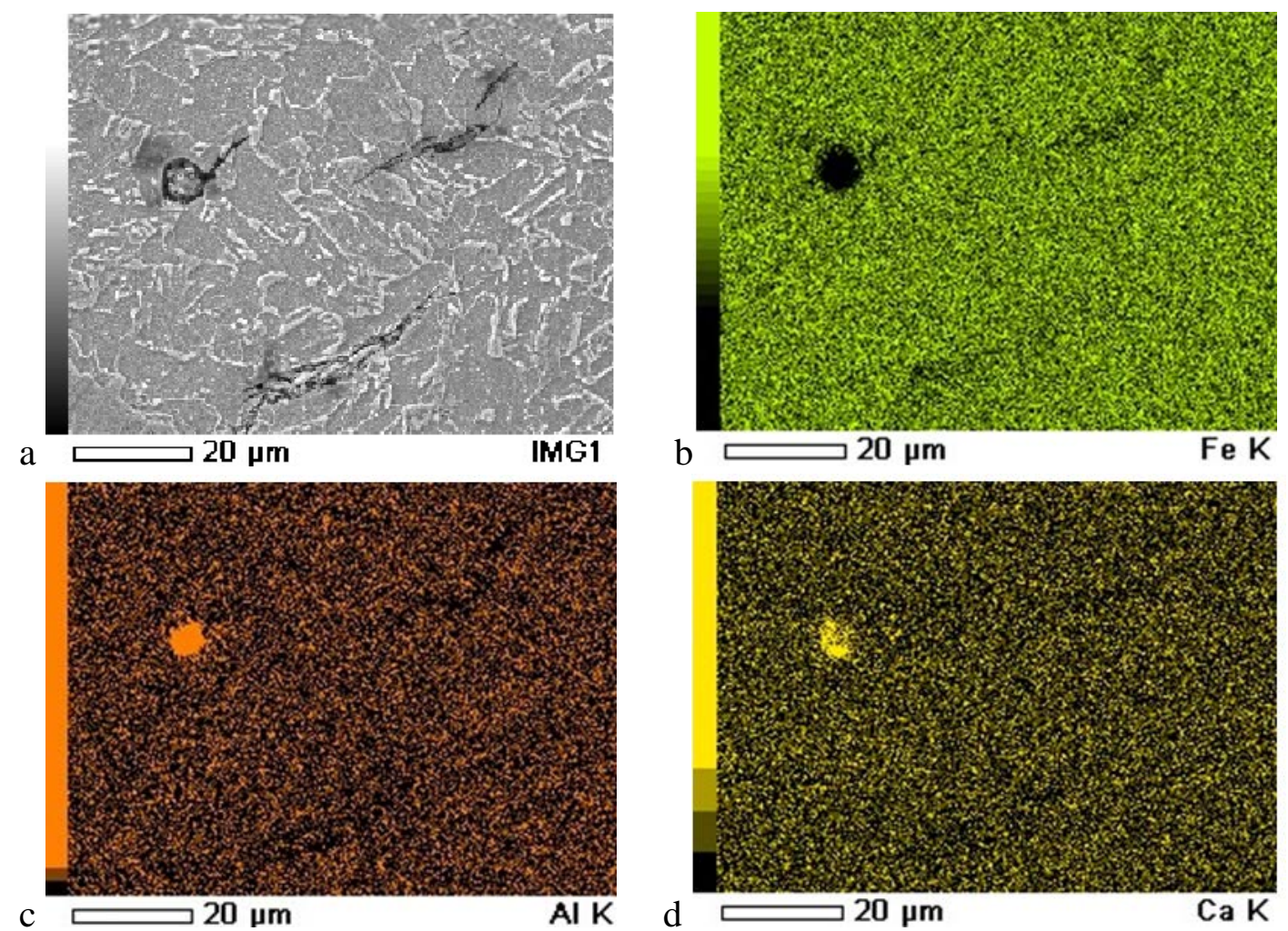

Fig. 3. SEM micrograph of FGB sample showing crack initiation at $\mathrm{Al}$, Ca oxide (a) with corresponding X-ray maps of $\mathrm{Fe}(\mathrm{b}), \mathrm{Al}$ (c) and $\mathrm{Ca}(\mathrm{d})$.

Results of trace analysis are summarised in Table 2. Transgranular cracking was observed on the cleavage $\{001\}$ planes and on $\{110\},\{112\}$ and $\{123\}$ slip planes, without a clear preferential trend. Branching of HIC also followed the same crystallographic planes. Analysis of grain orientations showed that grains with the same crack plane exhibit wide orientation spread, e.g. there was no preferential orientation for crack development. The results support the suggestion that the resistance to HIC could be improved by introducing texture control in such a way that grains have orientation unfavourable for operation of cleavage and slip planes [10]. Similar to the results of 
[10], which indicated less susceptibility to HIC of microstructures with higher fraction of LAGBs, arrest of the crack propagation was observed in some cases at low angle boundaries (Fig. 5).
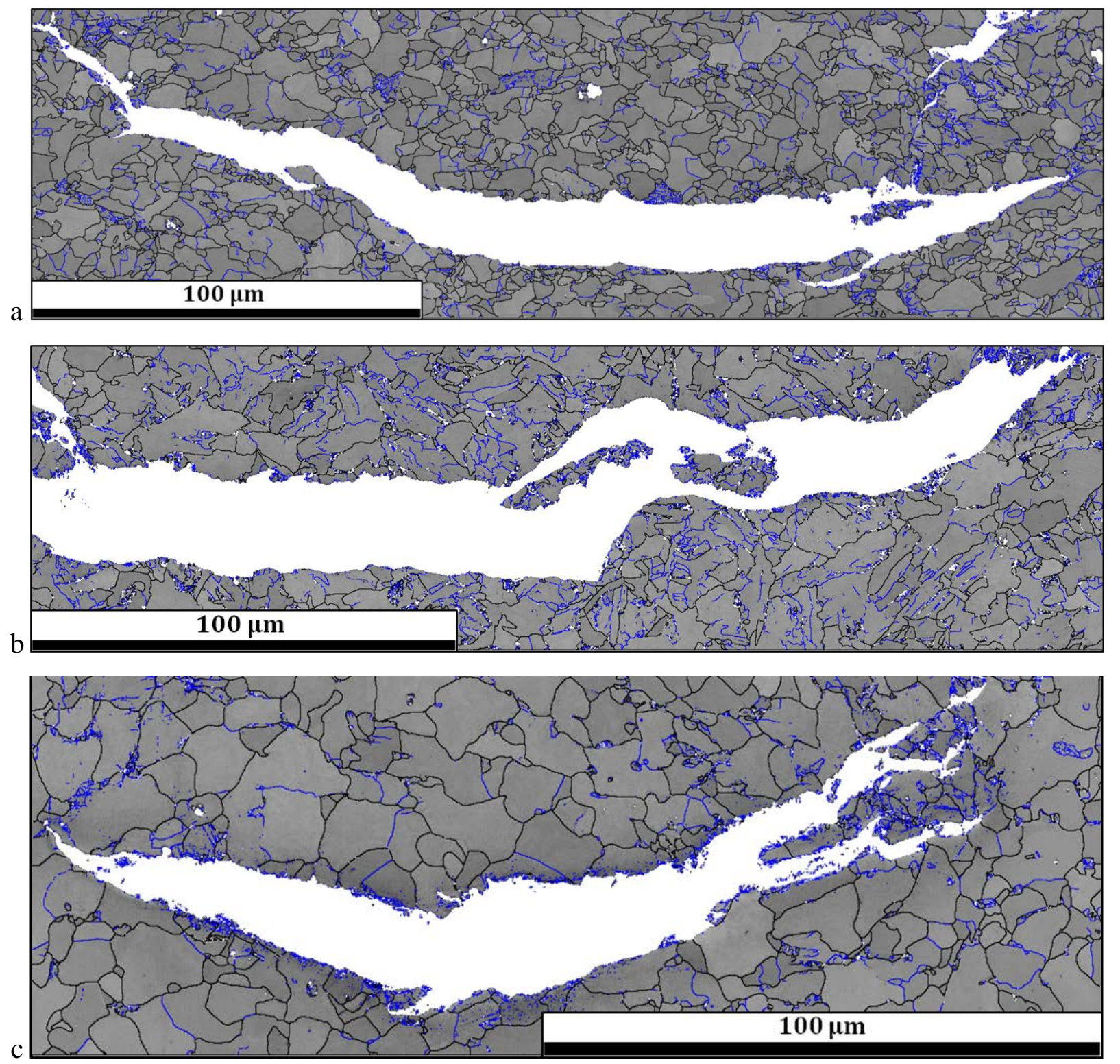

Fig. 4. Band contrast maps showing crack propagation in (a) BFP, (b) BF and (c) EPF microstructures. LAGB = blue, HAGB = black and transverse direction (TD) = horizontal. Step size $=0.15 \mu \mathrm{m}$.

\section{Conclusions}

The results have shown that steel microstructure has a pronounced effect on the rate of hydrogeninduced blistering and internal crack initiation, being the fastest in ferrite-pearlite microstructure. In some cases, oxide inclusions/matrix and pearlite-ferrite interfaces were deemed to be the crack initiation sites. However, HIC was found to be predominantly transgranular along $\{001\},\{110\}$, $\{112\}$ and $\{123\}$ planes without a clear preferential trend. HIC branching was observed to be along these planes, whereas low angle boundaries were able to arrest crack propagation.

\section{Acknowledgement}

The authors would like to thank the Australian Research Council (LP0883546) and BlueScope Steel Ltd. for their financial support. 

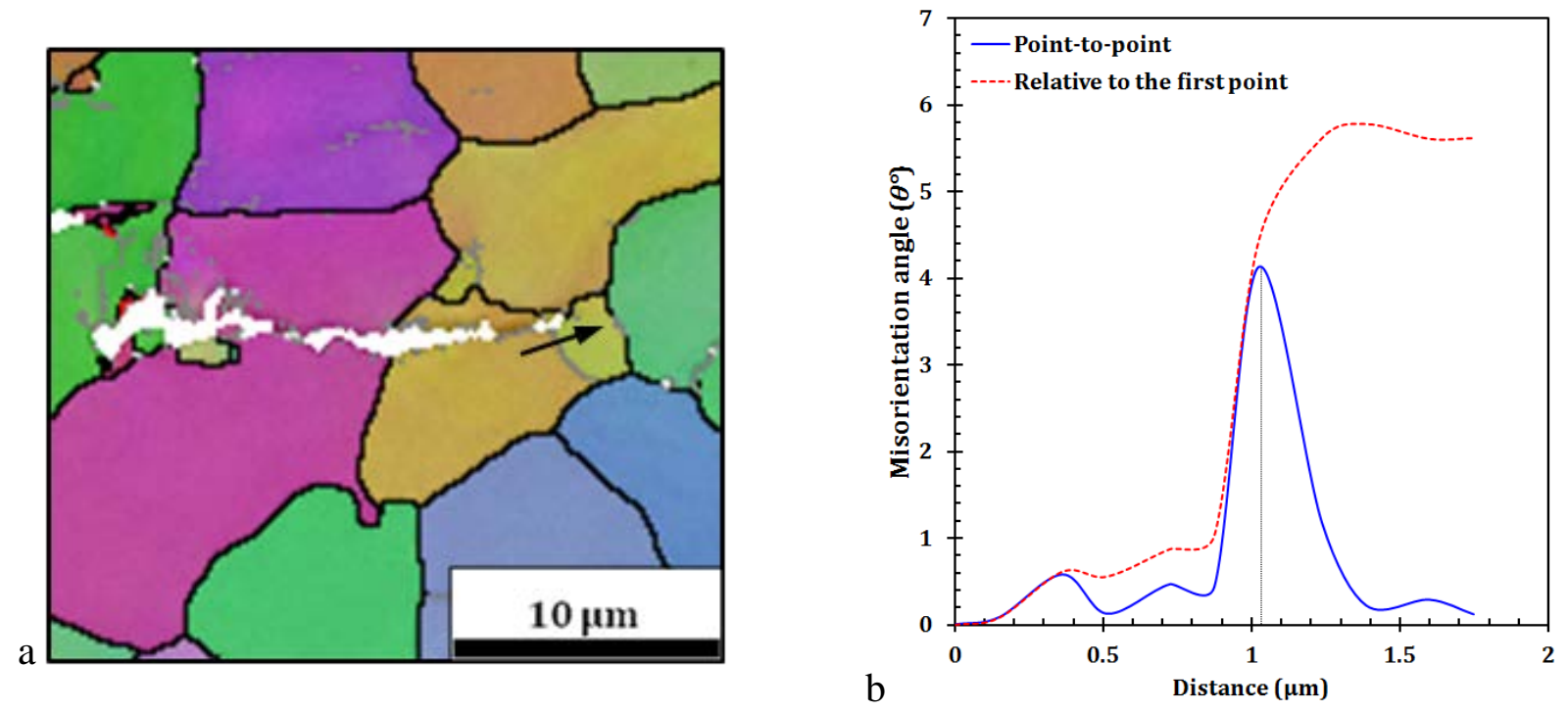

Fig. 5. (a) Magnified view of crack arrest at low angle grain boundary in the EFP sample. (b) Misorientation profile along the solid black arrow in (a).

\section{References}

[1] J.P. Hirth, Theories of hydrogen induced cracking of steels, in: R. Gibala, R.F. Hehemann (Eds.), Hydrogen Embrittlement and Stress Corrosion Cracking, ASM International, Materials Park, OH, 1984, pp. 30-41.

[2] M.T. Shehata, M. Elboujdaini, W. Revie, Initiation of stress corrosion cracking and hydrogeninduced cracking in oil and gas line-pipe steels, in: G. Pluvinage, M.H. Elwanty (Eds.), Safety, Reliability and Risks Associated with Water, Oil and Gas Pipelines, Springer, The Netherlands, 2008, pp. 115-128.

[3] S.K. Yen, I.B. Huang, Critical hydrogen concentration for hydrogen-induced blistering on AISI 430 stainless steel, Mater. Chem. Physics 80 (2003) 662-666.

[4] X.C. Ren, Q.I. Zhou, G.B. Shan, W.Y. Chu, J.X. Li, Y.J. Su, L.J. Qiao, A nucleation mechanism of hydrogen blister in metals and alloys, Metall. Mater. Trans. A, 39A (2008) 88-97.

[5] D. Pérez Escobar, C. Miñambres, L. Duprez, K. Verbeken, M. Verhaege, Internal and surface damage of multiphase steels and pure iron after electrochemical hydrogen charging, Corros. Sci., 53 (2011) 3166-3176.

[6] H-L. Lee, S.L-I. Chan, Hydrogen embrittlement of AISI 4130 steel with an alternate ferrite/pearlite banded structure, Mater. Sci. Eng, A 142 (1991) 193-201.

[7] G.T. Park, S. U. Koh, H.G. Jung, K. Y. Kim, Effect of microstructure on the hydrogen trapping efficiency and hydrogen induced cracking of linepipe steel, Corros. Sci. 50 (2008) 1865-1871.

[8] W.K. Kim, S.U. Koh, B.Y. Yang, K.Y. Kim, Effect of environmental and metallurgical factors on hydrogen induced cracking of HSLA steels, Corros. Sci. 50 (2008) 3336-3342.

[9] H.B. Xue, Y.F. Cheng, Characterization of inclusions of X80 pipeline steel and its correlation with hydrogen-induced cracking, Corros. Sci. 53 (2011) 1201-1208.

[10] V. Venegas, F. Caleyo, T. Baudin, J.H. Espina-Hernández, J.M. Hallen, On the role of crystallographic texture in mitigating hydrogen-induced cracking in pipeline steels, Corros. Sci. 53 (2011) 4204-4212.

[11] D. Hejazi, A.J. Haq, N. Yazdipour, D.P. Dunne, A. Calka, F. Barbaro, E.V. Pereloma, Effect of manganese content and microstructure on the susceptibility of X70 pipeline steel to hydrogen cracking, Mater.Sci.Eng. A, 551 (2012) 40-49.

[12] AS/NZS 3752-2006 Welding and allied processes - determination of hydrogen content in ferritic steel arc weld metal, Australia Standards, 2006, 29 p. 
[13] S. Kim, T.J. Marrow, Application of electron backscattered diffraction to cleavage fracture in duplex stainless steel, Scr. Mater. 40 (1999) 1395-1400. 